\title{
PET Imaging of Copper Trafficking in a Mouse Model of Alzheimer Disease
}

\author{
Julia Baguña Torres*1, Erica M. Andreozzi*1, Joel T. Dunn ${ }^{1}$, Muhammad Siddique ${ }^{1}$, Istvan Szanda ${ }^{1}$, David R. Howlett ${ }^{2}$, \\ Kavitha Sunassee ${ }^{1}$, and Philip J. Blower ${ }^{1}$ \\ ${ }^{1}$ King's College London, Division of Imaging Sciences and Biomedical Engineering, St. Thomas' Hospital, London, United Kingdom; \\ and ${ }^{2}$ King's College London, Wolfson Centre for Age-Related Diseases, London, United Kingdom
}

\begin{abstract}
Alzheimer disease (AD) is a fatal neurodegenerative disorder characterized by progressive neuronal loss and cognitive decline. The lack of reliable and objective diagnostic markers for AD hampers early disease detection and treatment. Growing evidence supports the existence of a dysregulation in brain copper trafficking in $A D$. The aim of this study was to investigate brain copper trafficking in a transgenic mouse model of AD by PET imaging with ${ }^{64} \mathrm{Cu}$, to determine its potential as a diagnostic biomarker of the disorder. Methods: Brain copper trafficking was evaluated in 6- to 8-mo-old TASTPM transgenic mice and age-matched wild-type controls using the ${ }^{64} \mathrm{Cu}$ bis(thiosemicarbazone) complex ${ }^{64} \mathrm{Cu}-$ GTSM (glyoxalbis( $\left(N^{4}\right.$-methyl-3-thiosemicarbazonato) copper(II)), which crosses the blood-brain barrier and releases ${ }^{64} \mathrm{Cu}$ bioreductively into cells. Animals were intravenously injected with ${ }^{64} \mathrm{Cu}-$ GTSM and imaged at 0-30 min and 24-25 $\mathrm{h}$ after injection. The images were analyzed by atlas-based quantification and texture analysis. Regional distribution of ${ }^{64} \mathrm{Cu}$ in the brain $24 \mathrm{~h}$ after injection was also evaluated via ex vivo autoradiography and compared with amyloid- $\beta$ plaque deposition in TASTPM mice. Results: Compared with controls, in TASTPM mice PET image analysis demonstrated significantly increased (by a factor of $\sim 1.3$ ) brain concentration of ${ }^{64} \mathrm{Cu}$ at $30 \mathrm{~min}(P<0.01)$ and $24 \mathrm{~h}(P<0.05)$ after injection of the tracer and faster (by a factor of $\sim 5$ ) ${ }^{64} \mathrm{Cu}$ clearance from the brain $(P<0.01)$. Atlas-based quantification and texture analysis revealed significant differences in regional brain uptake of ${ }^{64} \mathrm{Cu}$ and PET image heterogeneity between the 2 groups of mice. Ex vivo autoradiography showed that regional brain distribution of ${ }^{64} \mathrm{Cu}$ at $24 \mathrm{~h}$ after injection did not correlate with amyloid- $\beta$ plaque distribution in TASTPM mice. Conclusion: The trafficking of ${ }^{64} \mathrm{Cu}$ in the brain after administration of ${ }^{64} \mathrm{Cu}$-GTSM is significantly altered by AD-like pathology in the TASTPM mouse model, suggesting that ${ }^{64} \mathrm{Cu}-\mathrm{GTSM}$ PET imaging warrants clinical evaluation as a diagnostic tool for $A D$ and possibly other neurodegenerative disorders.
\end{abstract}

Key Words: copper trafficking; Alzheimer's disease; positron emission tomography; ${ }^{64} \mathrm{Cu}$

J Nucl Med 2016; 57:109-114

DOI: 10.2967/jnumed.115.162370

\footnotetext{
Received Jun. 28, 2015; revision accepted Sep. 28, 2015.

For correspondence or reprints contact: Philip Blower, Division of Imaging Sciences and Biomedical Engineering, King's College London, St. Thomas' Hospital, London, SE1 7EH U.K.

E-mail: philip.blower@kcl.ac.uk

${ }^{*}$ Contributed equally to this work.

Published online Oct. 8, 2015.

COPYRIGHT (c) 2016 by the Society of Nuclear Medicine and Molecular Imaging, Inc.
}

A lzheimer disease (AD) is the most common form of dementia in the elderly. Its prevalence in an ageing global population is rapidly increasing, creating a major socioeconomic burden. There is no satisfactory method for its early diagnosis and no effective treatment to halt or delay the cognitive decline experienced by patients. Currently, the most promising application of molecular imaging in $\mathrm{AD}$ is the visualization of amyloid- $\beta(\mathrm{A} \beta)$ burden using PET radioligands that bind specifically to $\mathrm{A} \beta$ plaques, such as the ${ }^{11} \mathrm{C}$-Pittsburgh compound $\mathrm{B},{ }^{18} \mathrm{~F}$-florbetaben, ${ }^{18} \mathrm{~F}$-florbetapir, and ${ }^{18} \mathrm{~F}$-flutemetamol (1). Nevertheless, clinical data indicate that imageable $\mathrm{A} \beta$ plaque load alone is not an adequate predictor of disease progression $(2,3)$; many subjects with high $\mathrm{A} \beta$ burden detected by PET did not subsequently develop $\mathrm{AD}$, and there is a need for PET radiotracers for a wider range of molecular features of the disorder (4).

In recent years, there has been growing evidence associating changes in trafficking and distribution of trace metals, including copper, with the onset and progression of $\operatorname{AD}(5,6)$. Whether this association is a cause or consequence of the pathology is unknown, and the nature of the changes is poorly understood. Copper has been found to interact with key components of AD pathology (A $\beta$, amyloid precursor protein [APP], $\beta$-secretase 1 , tau) and, as a result, is thought to contribute to amyloidosis, synaptic toxicity, and oxidative stress $(7-11)$. A $\beta$ plaques have been described as sinks of iron, zinc, and copper ions $(12,13)$, which have been shown to enhance $A \beta$ aggregation and neurotoxicity $(14,15)$. It has been suggested that the association of copper with $A \beta$ aggregates and other molecular features of $\mathrm{AD}$ might also lead to decreased intracellular copper bioavailability and reduced activity of copper-dependent enzymes in the brain $(16,17)$.

This metal hypothesis of AD is the basis of the development of treatments aimed at minimizing copper-induced neurotoxicity and restoring brain copper homeostasis (18). Preclinical and clinical studies demonstrated reduced $A \beta$ burden, increased intracellular copper levels, and improved cognitive function after administration of copper(II) chelators (e.g., Clioquinol, PBT2) capable of stripping copper ions from $\mathrm{A} \beta$ plaque and redistributing them into cells (19-21). A recent investigation showed that treatment with glyoxalbis $\left(N^{4}\right.$-methyl-3-thiosemicarbazonato) copper(II) $(\mathrm{Cu}-$ GTSM) - a copper bis(thiosemicarbazone) complex that delivers copper into cells and releases it bioreductively (22)—enhanced cognitive performance in APP/PS1 transgenic AD mice by triggering neuroprotective mechanisms that inhibited GSK3 $\beta$ and decreased phosphorylated tau and $A \beta$ trimer levels (23). Hence, understanding the role of copper homeostasis in $\mathrm{AD}$ pathology may be critical to development of both novel diagnostics and therapeutics. 
A PET radiotracer able to measure brain copper trafficking in vivo could be a valuable tool to investigate changes in copper metabolism in the brain, to determine the potential of copper dyshomeostasis as an early diagnostic marker for $\mathrm{AD}$ and as a useful complement to other imaging biomarkers. Positron-emitting copper isotopes $\left({ }^{60} \mathrm{Cu},{ }^{61} \mathrm{Cu},{ }^{62} \mathrm{Cu},{ }^{64} \mathrm{Cu}\right)$ can in principle be used to study the trafficking of copper to, from, and within the brain, not only in animal models but also in humans, by PET imaging over a period of hours and repeatedly during the lifetime of the subject. Intravenous injection of ${ }^{64} \mathrm{Cu}$ in the form of ionic copper (II) salts leads to delivery of radiotracer to the brain via native copper transport processes in quantities that are insufficient for meaningful imaging $(24,25)$. However, by exploiting the ability of uncharged lipophilic copper(II) complexes, such as Cu-GTSM, to penetrate the bloodbrain barrier and release their copper payload nonselectively into cells (26), the intracellular copper pool can be supplemented with tracer quantities of ${ }^{64} \mathrm{Cu}$ sufficient to allow imaging of its subsequent trafficking. A preliminary study by Fodero-Tavoletti et al. showed that $60 \mathrm{~min}$ after ${ }^{64} \mathrm{Cu}$-labeled $\mathrm{Cu}-\mathrm{GTSM}$ was administered intravenously, brain uptake of ${ }^{64} \mathrm{Cu}$ as measured by ex vivo $\gamma$-counting was significantly greater in APP/PS1 mice than in their age-matched wild-type counterparts (27). Following up on this work, in the present study we explore further the trafficking of copper in AD by PET imaging with ${ }^{64} \mathrm{Cu}-\mathrm{GTSM}$ in the APPswe $\mathrm{x}$ PS1.M146V (TASTPM) transgenic mouse model. TASTPM mice rapidly develop some of the key pathologic features of $\mathrm{AD}$, such as cerebral $\mathrm{A} \beta$ plaque deposition, neuronal loss, and neuroinflammation, showing impaired cognitive function at 6 mo of age $(28,29)$. The visualization, mapping, and monitoring of ${ }^{64} \mathrm{Cu}$ trafficking in this model of AD will provide valuable information to determine the potential of imaging brain copper trafficking as a diagnostic marker for AD.

\section{MATERIALS AND METHODS}

Full experimental details for the radiosynthesis of ${ }^{64} \mathrm{Cu}-\mathrm{GTSM}$ $(26,30,31)$, used animal models, solvent extraction method for determination of ${ }^{64} \mathrm{Cu}-\mathrm{GTSM}$ in brain tissue, nanoPET imaging (32), PET image analysis (33), texture analysis $(34,35)$, ex vivo biodistribution, brain autoradiography, histology, and statistical analysis are reported in the supplemental materials (available at http://jnm.snmjournals. org). Animal experiments were performed in accordance with the Animals (Scientific Procedures) Act, 1986, and approved by the local ethics committee.

\section{RESULTS}

\section{Solvent Extraction}

To assess the ability of ${ }^{64} \mathrm{Cu}-\mathrm{GTSM}$ to release ${ }^{64} \mathrm{Cu}$ intracellularly within the brain, we determined the amount of intact complex in brain homogenates of mice injected with ${ }^{64} \mathrm{Cu}-\mathrm{GTSM}$ using a previously reported octanol-extraction method (36). Almost all ${ }^{64} \mathrm{Cu}$ partitioned in the aqueous/protein-bound in both TASTPM mice and age-matched controls; $3.81 \% \pm 2.98 \%$ of brain ${ }^{64} \mathrm{Cu}$ radioactivity was associated with the octanol fraction at $30 \mathrm{~min}$ and $2.82 \% \pm 0.14 \%$ at $24 \mathrm{~h}$ after injection. Radio-thin-layer chromatography showed that even the octanol-extractable fraction contained no intact ${ }^{64} \mathrm{Cu}-\mathrm{GTSM}$.

\section{PET Imaging}

Whole-body copper fluxes in vivo in TASTPM mice $(n=4)$ were imaged with ${ }^{64} \mathrm{Cu}$-GTSM from 0 to $30 \mathrm{~min}$ and from 24 to $25 \mathrm{~h}$ after injection and compared with wild-type controls $(n=6)$.
The general biodistribution of the tracer was similar for both animal groups (Fig. 1). At $30 \mathrm{~min},{ }^{64} \mathrm{Cu}$ radioactivity accumulated primarily in the heart, lungs, liver, intestines, kidneys, spinal cord, and brain in both TASTPM and wild-type mice. After $24 \mathrm{~h}$, a notable decrease in ${ }^{64} \mathrm{Cu}$ activity was observed in the lungs, kidneys, and heart, whereas ${ }^{64} \mathrm{Cu}$ concentration in the brain declined much less (Supplemental Fig. 1).

${ }^{64} \mathrm{Cu}$ biokinetics within the central nervous system (brain and spinal cord) were compared in AD mice and healthy controls using PET region-of-interest analysis (Fig. 2; Supplemental Fig. 2). PET quantification revealed that global average brain concentration of ${ }^{64} \mathrm{Cu}$ was significantly higher in TASTPM transgenic mice than in wild-type controls at $30 \mathrm{~min}(7.83 \pm 1.08$ vs. $5.57 \pm 0.70$ percentage injected dose per gram $[\% \mathrm{ID} / \mathrm{g}], P<0.01)$ and $24 \mathrm{~h}(7.04 \pm 0.94 \mathrm{vs}$. $5.46 \pm 0.70 \% \mathrm{ID} / \mathrm{g}, P<0.05)$. After $24 \mathrm{~h}$, a significant decrease in brain ${ }^{64} \mathrm{Cu}$ concentration was found in TASTPM mice $(-10.10 \% \pm$ $2.23 \%, P<0.01)$ but not in age-matched controls $(-2.04 \% \pm$ $3.57 \%, P>0.05)$. TASTPM mice also exhibited significantly higher ${ }^{64} \mathrm{Cu}$ concentration in the spinal cord than controls at both $30 \mathrm{~min}$ $(5.20 \pm 0.67$ vs. $3.73 \pm 0.54 \% \mathrm{ID} / \mathrm{g}, P<0.01)$ and $24 \mathrm{~h}(4.65 \pm$ 0.46 vs. $3.48 \pm 0.46 \% \mathrm{ID} / \mathrm{g}, P<0.05)$.

\section{Atlas-Based Image Analysis of Regional Brain Concentration of ${ }^{64} \mathrm{Cu}$}

As depicted in Figure 3 (Supplemental Fig. 3), ${ }^{64} \mathrm{Cu}-\mathrm{GTSM}$ distribution in the brains of both wild-type and TASTPM mice was heterogeneous both at $30 \mathrm{~min}$ and at $24 \mathrm{~h}$. To quantify heterogeneity in a functional/anatomic context, brain PET images were analyzed using a 3-dimensional mouse brain atlas (Fig. 4). TASTPM mice showed higher ${ }^{64} \mathrm{Cu}$ concentration than controls in all defined regions, reaching statistical significance in the medulla $(P<0.05)$, cerebellum $(P<0.01)$, midbrain $(P<0.001)$, hippocampus $(P<0.05)$, thalamus $(P<0.01)$, hypothalamus $(P<$ $0.05)$, pallidum $(P<0.05)$, olfactory bulb $(P<0.001)$, and corpus callosum $(P<0.05)$ at $30 \mathrm{~min}$, and in the medulla $(P<$ $0.001)$, cerebellum $(P<0.01)$, midbrain $(P<0.05)$, hypothalamus $(P<0.01)$, olfactory bulb $(P<0.05)$, and pons $(P<0.05)$ at $24 \mathrm{~h}$ (Supplemental Table 1).

\section{Texture Analysis}

Statistical data emerging from texture analysis are listed in the supplemental data (Supplemental Table 2). The TASTPM group showed increased SD $(P<0.05)$ and coefficient of variation $(P<$ $0.01)$ compared with controls, demonstrating a higher spread and nonuniformity in voxel intensity values. TASTPM brain images had also higher entropy $(P<0.01)$ than those of wild-type mice, revealing an increased level of disorder in voxel intensity distribution. The energy of TASTPM brain images was lower $(P<$ $0.05)$ than that of control datasets, suggesting a broader histogram and spread of voxel intensity values. The TASTPM group also showed a lower kurtosis $(P<0.01)$ than controls, which is indicative of a voxel intensity distribution less clustered around the mean and more spread, compared with the control group. Skewness was more negative $(P<0.01)$ for controls than for TASTPM mice, indicating a greater spread for voxel intensity values lower than the median than for those higher than the median in wild-type datasets. All measures of central tendency of the datasets (mean, median, maximum, minimum, range, and percentiles) were higher for the TASTPM group than for wild-type mice, which is indicative of increased tracer uptake in the brains of TASTPM mice compared with controls. 


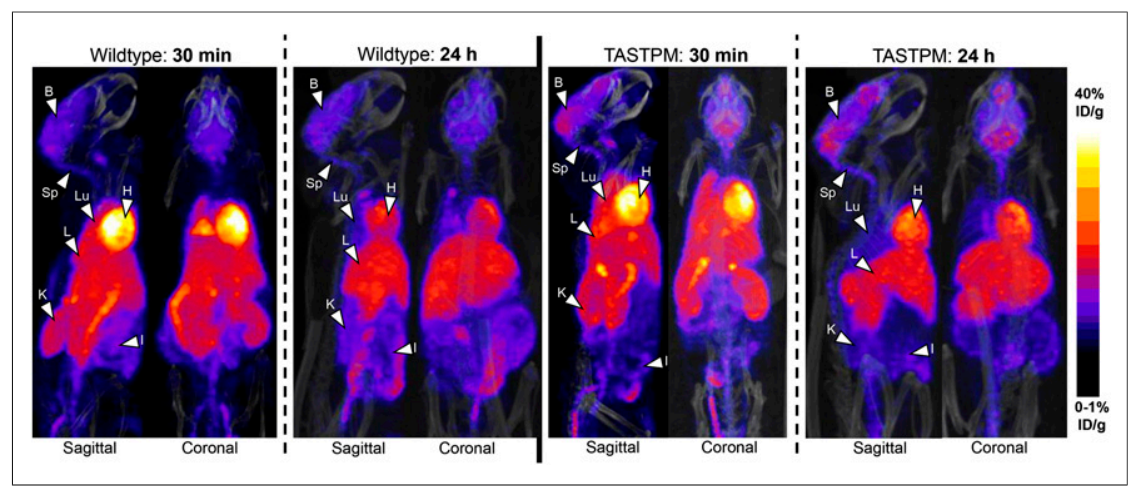

FIGURE 1. Exemplar sagittal and coronal PET/CT images of wild-type controls and TASTPM mice at $30 \mathrm{~min}$ and $24 \mathrm{~h}$ after administration of ${ }^{64} \mathrm{Cu}-\mathrm{GTSM}$. Organs are indicated by arrows. $\mathrm{B}=$ brain; $\mathrm{H}=$ heart; $\mathrm{I}=$ intestines; $\mathrm{K}=$ kidneys; $\mathrm{L}=$ liver; $\mathrm{Lu}=$ lungs; $\mathrm{Sp}=$ spinal cord.

\section{Ex Vivo Biodistribution}

After PET imaging, the ex vivo biodistribution of ${ }^{64} \mathrm{Cu}$ at $24 \mathrm{~h}$ after injection of ${ }^{64} \mathrm{Cu}$-GTSM was evaluated by $\gamma$-counting of explanted organs (Fig. 5). Only lung tracer uptake was found to differ significantly between groups and was higher in TASTPM than controls $(21.30 \pm 5.39$ vs. $17.54 \pm 1.22 \% \mathrm{ID} / \mathrm{g}, P<0.05)$. Global brain uptake was consistently raised in TASTPM mice compared with age-matched controls, but by the tests used the difference was not significant $(P>0.05)$. The brain $\% \mathrm{ID} / \mathrm{g}$ values determined by ex vivo organ counting showed a moderately strong correlation $\left(r^{2}=0.61\right)$ with whole-brain uptake measured by PET (Supplemental Fig. 4).

\section{Ex Vivo Brain Autoradiography}

To evaluate further the heterogeneity in the brain distribution of ${ }^{64} \mathrm{Cu}$, sagittal brain slices of TASTPM $(n=4)$ and control mice $(n=6)$ sacrificed $24 \mathrm{~h}$ after ${ }^{64} \mathrm{Cu}-\mathrm{GTSM}$ injection were imaged using phosphor imaging autoradiography. Ex vivo autoradiographs (Fig. 6) confirmed heterogeneous ${ }^{64} \mathrm{Cu}$ uptake within brain tissue and the localization of radioactive hotspots in the medulla, cerebellum, pons, midbrain, caudate putamen, and olfactory bulb seen by PET imaging. Visual inspection of representative digital autoradiographs showed increased tracer uptake and greater heterogeneity in ${ }^{64} \mathrm{Cu}$ brain distribution in TASTPM mice compared with controls.

\section{Histology}

To determine whether the regional brain distribution of ${ }^{64} \mathrm{Cu}$ was related to $A \beta$ plaque deposition, TASTPM brain slices were autoradiographed and subsequently stained with Congo red (Fig. 7). Although ${ }^{64} \mathrm{Cu}$ was taken up by the entire brain, the areas with the most prominent radioactive hotspots (olfactory bulb, medulla, cerebellum, midbrain, pons, and caudate putamen) did not correspond to the regions with highest $A \beta$ plaque load (hippocampus, thalamus, and cerebral cortex).

\section{DISCUSSION}

In this study, we aimed to explore brain copper trafficking in TASTPM mice and age-matched controls at the earliest stage at which cognitive impairment can be detected in this transgenic model (i.e., 6 mo old) (28), by PET imaging using ${ }^{64} \mathrm{Cu}-\mathrm{GTSM}$. The chosen route of administration of ${ }^{64} \mathrm{Cu}-\mathrm{GTSM}$ was intravenous injection, which does not mimic the gastrointestinal uptake and biodistribution of endogenous copper but ensures rapid delivery of the radiotracer into the brain. To confirm the ability of the tracer to release radio- copper intracellularly within the brain, we used solvent extraction to measure the amount of intact (octanol-soluble) ${ }^{64} \mathrm{Cu}-\mathrm{GTSM}$ present in brain homogenates, at different time points after injection. The low ${ }^{64} \mathrm{Cu}$ present in the octanol-extractable fraction, and the lack of ${ }^{64} \mathrm{Cu}-\mathrm{GTSM}$ complex detectable by radio-thin-layer chromatography of that fraction, indicated that ${ }^{64} \mathrm{Cu}-\mathrm{GTSM}$ was almost completely dissociated by $30 \mathrm{~min}$. Combined with the PET imaging studies, which showed remarkably high and rapid ${ }^{64} \mathrm{Cu}$-GTSM uptake in the brain, this is consistent with a process in which the lipophilicity of the ${ }^{64} \mathrm{Cu}-\mathrm{GTSM}$ complex facilitates its passage across the blood-brain barrier and into cells where it dissociates, releasing ${ }^{64} \mathrm{Cu}$ intracellularly, as previously suggested for this family of compounds $(22,26,37,38)$. The speciation of the dissociated ${ }^{64} \mathrm{Cu}$ in the intracellular copper pool remains unknown.

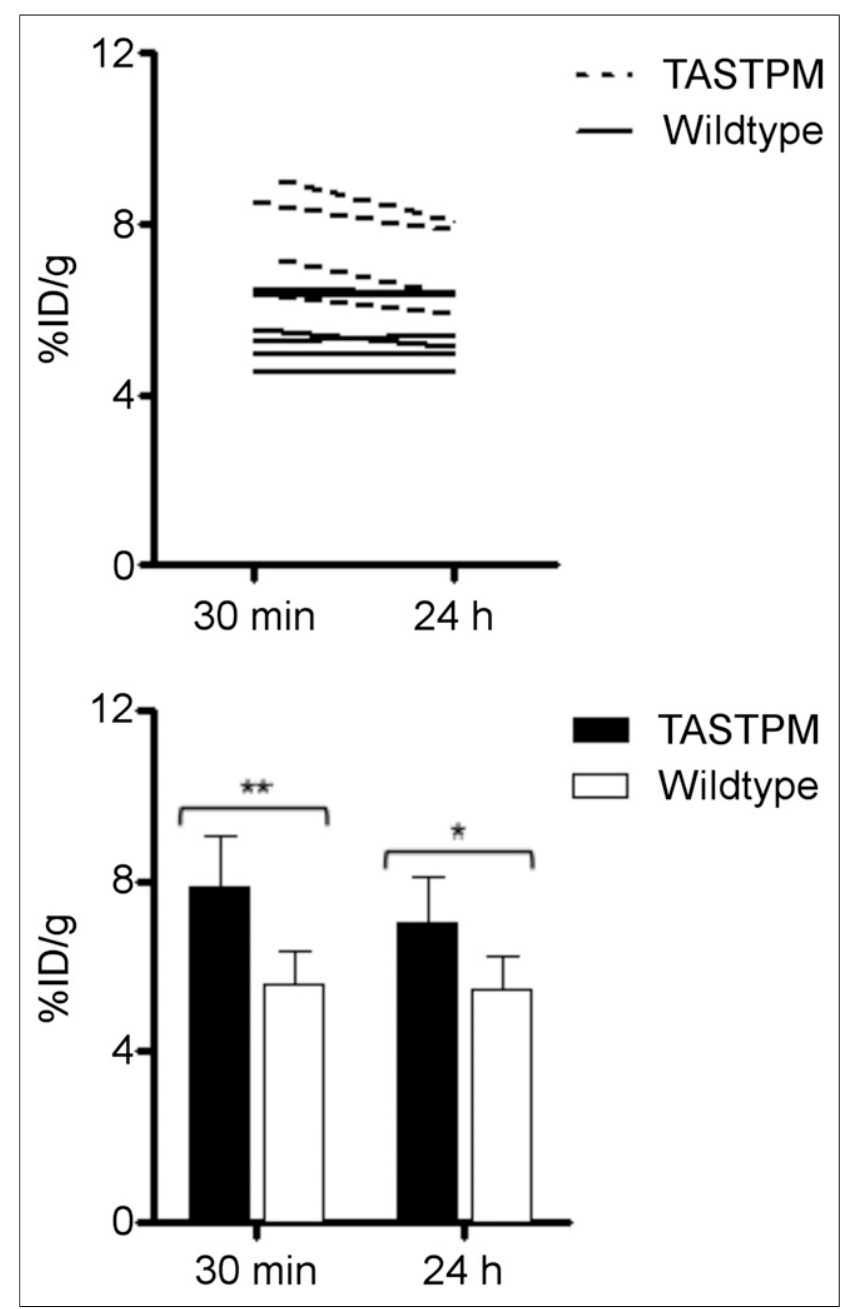

FIGURE 2. In vivo brain concentration of ${ }^{64} \mathrm{Cu}(\% \mathrm{ID} / \mathrm{g})$ and corresponding time-activity curves in TASTPM mice and wild-type controls measured by PET region-of-interest analysis. Significant differences, ${ }^{*} P<0.05$ and ${ }^{\star \star} P<0.01$. Data are mean ( $n=4$ for TASTPM mice; $n=6$ for controls $) \pm$ SD. Similar results were obtained for spinal cord (Supplemental Fig. 2). 


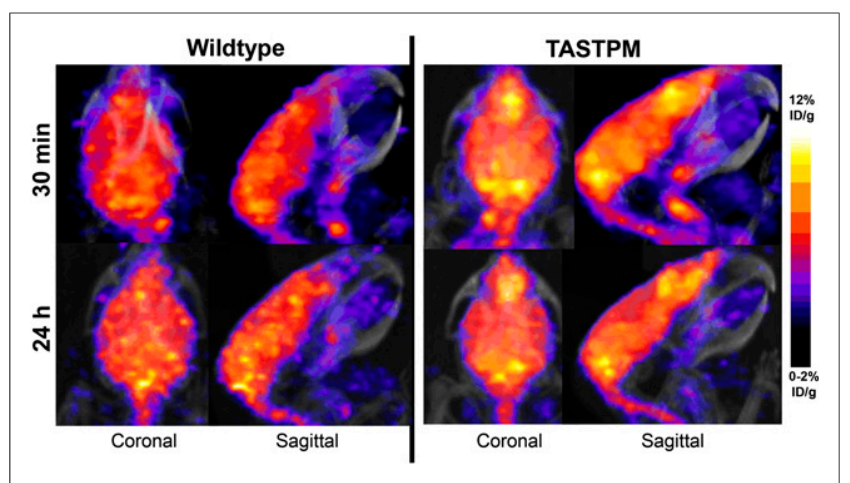

FIGURE 3. Representative PET/CT maximum-intensity-projection images illustrating heterogeneous distribution of ${ }^{64} \mathrm{Cu}$ in brains of wildtype and TASTPM mice at $30 \mathrm{~min}$ (top) and $24 \mathrm{~h}$ (bottom) after injection of ${ }^{64} \mathrm{Cu}$-GTSM. Images of all TASTPM $(n=4)$ and wild-type $(n=6)$ mice are included in supplemental materials (Supplemental Fig. 3).

${ }^{64} \mathrm{Cu}-\mathrm{GTSM}$ PET imaging also indicated that clearance of radiocopper from the brain was considerably slower than from most other tissues (e.g., heart, kidneys, lungs), for reasons not yet clear; it may be that brain tissue has greater active sequestration of copper ions driven by increased metabolic needs associated with regular brain function, or less active efflux mechanisms.

PET imaging of copper trafficking with ${ }^{64} \mathrm{Cu}-\mathrm{GTSM}$ revealed significantly increased brain and spinal cord uptake of ${ }^{64} \mathrm{Cu}$ in TASTPM mice at $30 \mathrm{~min}$ and $24 \mathrm{~h}$, compared with healthy controls. Despite differences in the animal model, age range, and methods used, these results agree with those reported by Fodero-Tavoletti et al. (27), who found enhanced ${ }^{64} \mathrm{Cu}$ brain concentration in the APP/PS1 mouse model of AD. Unlike PET, the increase in ${ }^{64} \mathrm{Cu}$ brain uptake in TASTPM mice, compared with controls, measured by ex vivo $\gamma$-counting at $24 \mathrm{~h}$ after injection of the tracer did not reach statistical significance; ex vivo organ counting is subject to greater opportunities for nonsystematic error (e.g., cross contamination between tissues during dissection, weighing errors, incomplete explantation) that may account for this discrepancy. This may also explain why $\gamma$-counting measurements did not show a stronger linear correlation with PET quantitative data $\left(r^{2}=0.61\right)$.

Although ${ }^{64} \mathrm{Cu}$ clearance from the brain was slower than that from other tissues in both TASTPM and wild-type mice, washout between $30 \mathrm{~min}$ and $24 \mathrm{~h}$ was significantly faster, by a factor of 5 , in TASTPM mice than in healthy controls $(-10 \%$ vs. $-2 \%)$. Nevertheless, TASTPM mice still had significantly higher ${ }^{64} \mathrm{Cu}$ concentration in the brain than controls both at $30 \mathrm{~min}$ and at $24 \mathrm{~h}$. These differences in brain copper trafficking between the 2 groups may be due to more active copper influx and efflux mechanisms in the TASTPM model, or different patterns of copper bioavailability to these processes. The molecular mechanisms underlying the increased uptake in TASTPM brains have yet to be elucidated; increased uptake may be driven by the regulation of total brain copper levels in an effort to maintain brain copper homeostasis or enhance copper-dependent antioxidant enzyme activity as a response to oxidative stress. On the other hand, faster brain clearance of ${ }^{64} \mathrm{Cu}$ in TASTPM transgenic mice may be caused by the overexpression of APP, for which a role in normal copper metabolism as an efflux transporter has been suggested (11).

Both PET and ex vivo autoradiography demonstrated that accumulation of ${ }^{64} \mathrm{Cu}$ within the brain at $30 \mathrm{~min}$ and $24 \mathrm{~h}$ was heterogeneous. Seeking to rationalize this ${ }^{64} \mathrm{Cu}$ heterogeneity, we measured ${ }^{64} \mathrm{Cu}$ brain regional uptake using a 3-dimensional mouse brain atlas and found it to be higher in all brain regions in TASTPM mice than in controls, with differences between the 2 groups reaching statistical significance in specific areas at $30 \mathrm{~min}$ and $24 \mathrm{~h}$ after injection of the tracer. Many of these brain regions are small compared with the limited spatial resolution of the PET/CT scanner. The heterogeneity in ${ }^{64} \mathrm{Cu}$ concentration will therefore inevitably have been underestimated by atlas-based quantification due to the partial-volume effect; combined with the lack of flexibility of segmentation boundaries and the potential for imperfect matching of atlas regions onto real brain images, these results must be interpreted cautiously.

To avoid subjectivity in interpreting regional variations in brain uptake of ${ }^{64} \mathrm{Cu}$ because of these limitations, PET brain signal heterogeneity was alternatively measured by texture analysis, which interrogates global and regional patterns of image heterogeneity

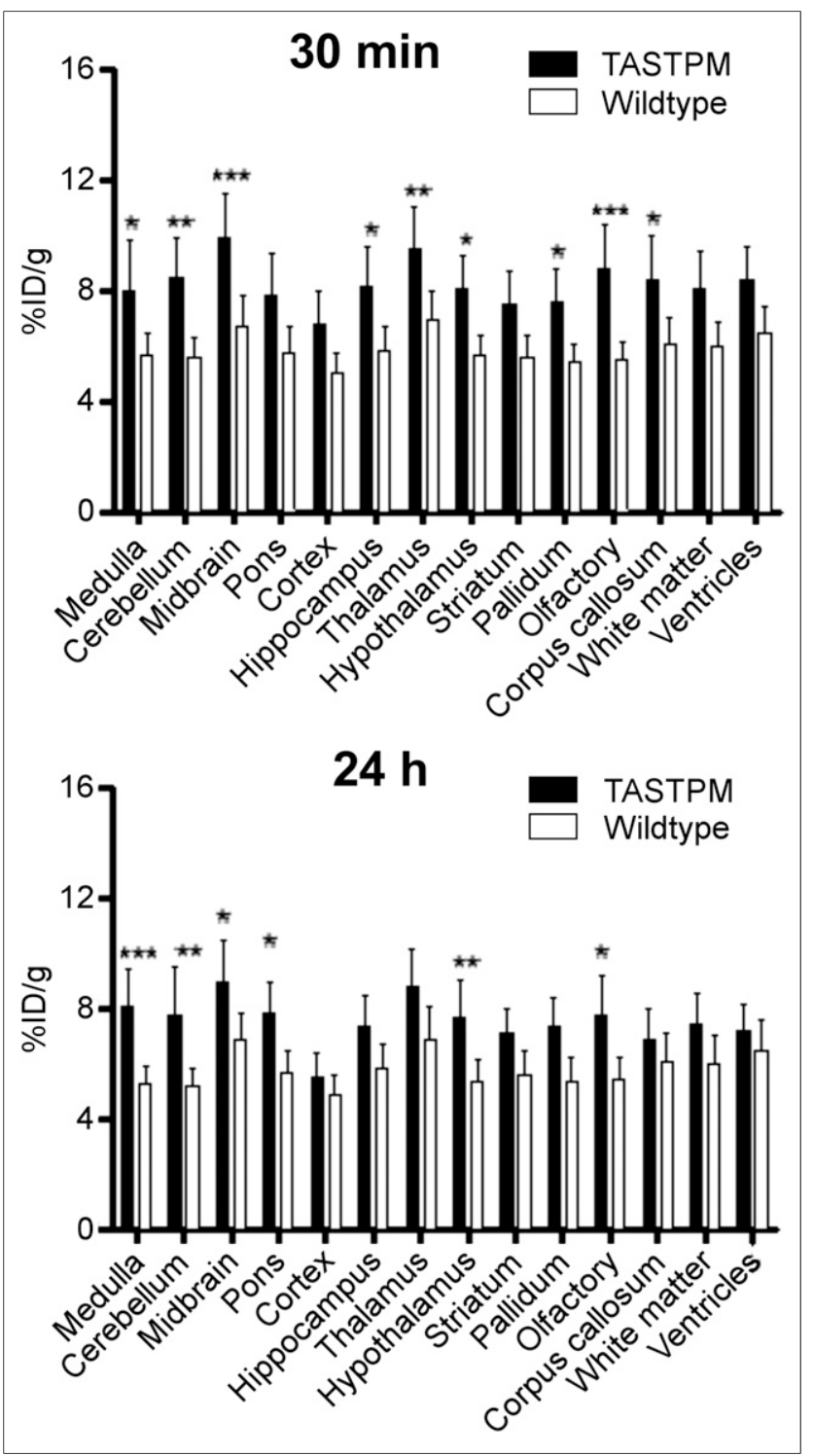

FIGURE 4. Regional brain distribution of ${ }^{64} \mathrm{Cu}$ in TASTPM mice and controls at $30 \mathrm{~min}$ (top) and $24 \mathrm{~h}$ (bottom). Statistically significant differences, ${ }^{\star} P<0.05,{ }^{\star \star} P<0.01$, and ${ }^{\star \star *} P<0.001$. Data are mean $(n=4$ for TASTPM mice; $n=6$ for controls) \pm SD. 


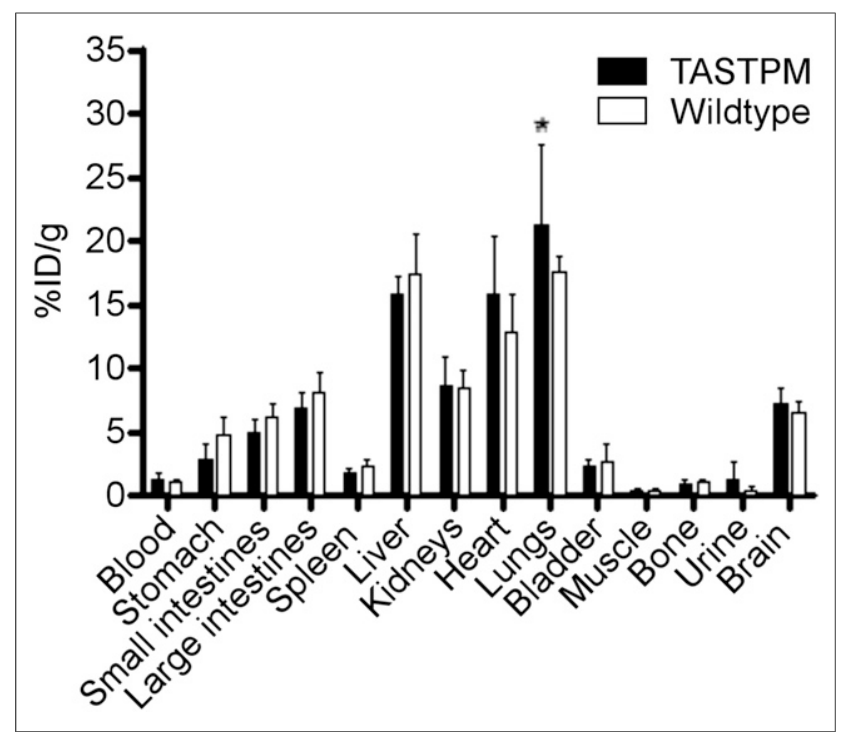

FIGURE 5. Tissue biodistribution (ex vivo) of ${ }^{64} \mathrm{Cu}$ in 6- to 8-mo-old TASTPM mice and age-matched controls at $24 \mathrm{~h}$ after injection of ${ }^{64} \mathrm{Cu}$-GTSM. Statistically significant differences from controls, ${ }^{*} P<0.05$. Data are mean ( $n=4$ for TASTPM mice; $n=6$ for controls) \pm SD.

without an underlying biologic or structural model. Statistical analysis of first-order texture parameters revealed a higher spread, asymmetry, and nonuniformity of the voxel intensity distribution in TASTPM brain images, indicating a greater degree of image heterogeneity in the disease model than controls. Although this does not offer a biologic interpretation of differences in brain uptake of ${ }^{64} \mathrm{Cu}$ between the 2 animal groups, it does offer a basis for parameterization of imaging for clinical diagnostic purposes.

The sequestration of copper by extracellular $A \beta$ plaque deposits is thought to contribute to brain copper dyshomeostasis in AD by reducing the intracellular bioavailability of copper ions $(6,12,13,39,40)$. To determine the extent of correlation between the regional distribution of ${ }^{64} \mathrm{Cu}$ in the brain and $\mathrm{A} \beta$ plaque deposition in TASTPM mice, brain sections were imaged by

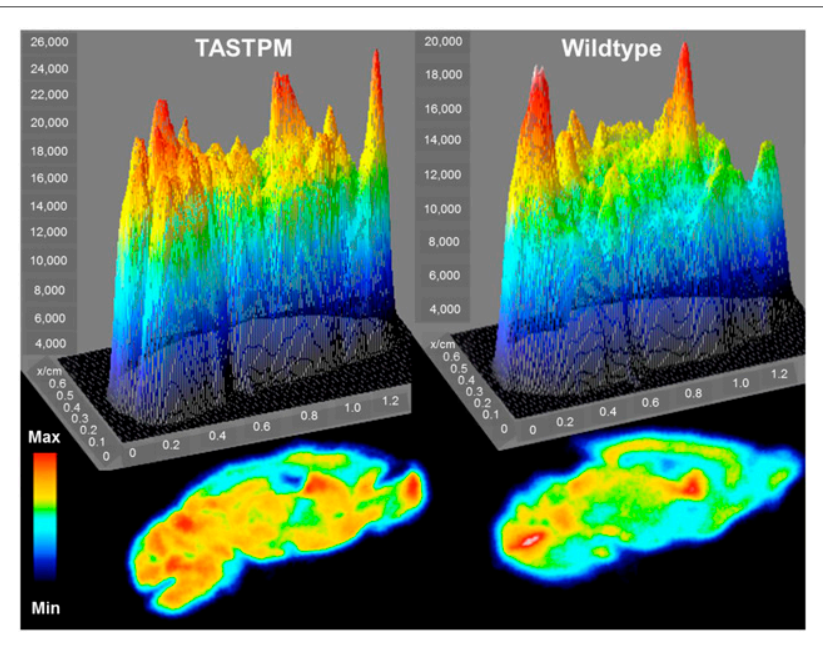

FIGURE 6. Surface plots of brain autoradiographs from 6- to 8-mo-old TASTPM (left) and control (right) mouse sacrificed $24 \mathrm{~h}$ after administration of ${ }^{64} \mathrm{Cu}$-GTSM. Max = maximum; Min = minimum.

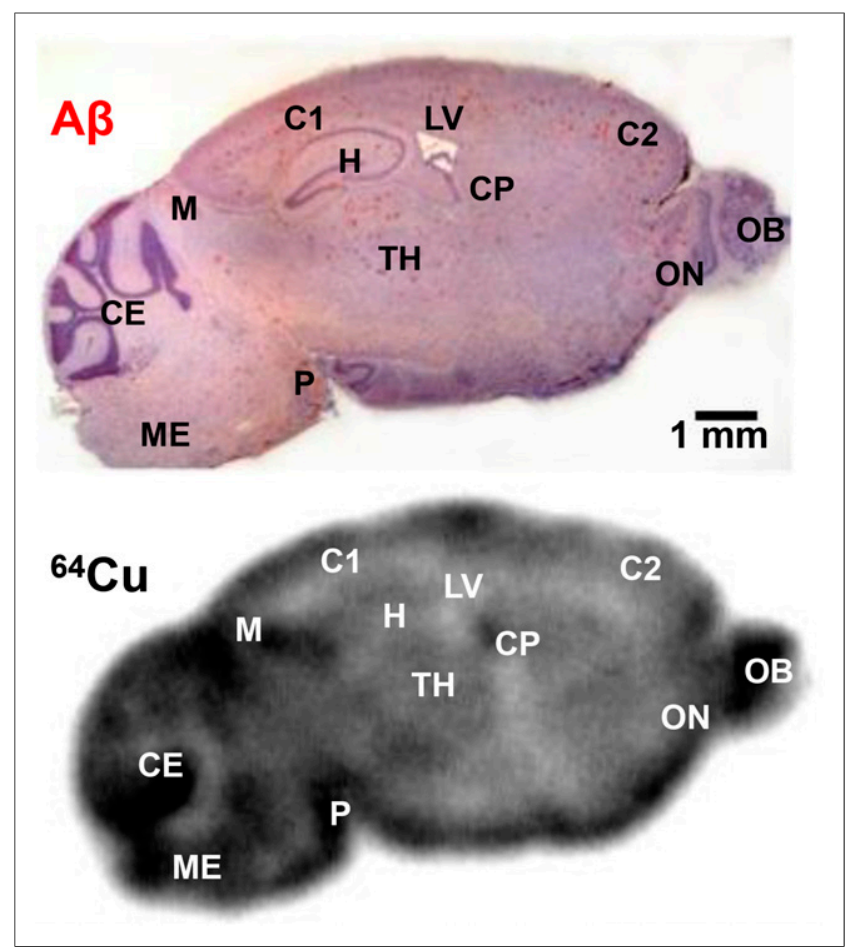

FIGURE 7. Photomicrograph of sagittal brain section from TASTPM mouse (top) and corresponding brain autoradiograph (bottom) $24 \mathrm{~h}$ after injection of ${ }^{64} \mathrm{Cu}-\mathrm{GTSM}$. C1 = cerebral cortex; C2 = cerebral cortex; $\mathrm{CE}=$ cerebellum; $\mathrm{CP}=$ caudate putamen; $\mathrm{H}=$ hippocampus; $\mathrm{LV}=$ lateral ventricle; $\mathrm{M}=$ midbrain; $\mathrm{ME}=$ medulla; $\mathrm{OB}=$ olfactory bulb; $\mathrm{ON}=$ anterior olfactory nucleus; $\mathrm{P}=$ pons; $\mathrm{TH}=$ thalamus.

autoradiography and subsequently stained with the $A \beta$-binding dye Congo red. The brain regions with the highest density of Congo red-positive amyloid deposits (hippocampus, thalamus, and cerebral cortex) showed the lowest accumulation of radioactivity among the brain regions observed in the autoradiographs of the same sections at $24 \mathrm{~h}$ after injection. This lack of correlation between the main radioactive hotspots and the regions of highest $\mathrm{A} \beta$ plaque load does not support the hypothesis that amyloid plaques serve as a sink for copper ions $(12,13)$, at least acutely, although it does not preclude the possibility that copper may accumulate in amyloid plaques chronically over the lifetime of the animal. It also suggests that metabolic/pathologic factors other than $A \beta$ plaque deposition may influence acute brain distribution of ${ }^{64} \mathrm{Cu}$, consistent with the view that amyloidosis may be a localized indicator of global disease.

\section{CONCLUSION}

${ }^{64} \mathrm{Cu}-\mathrm{GTSM}$ can effect efficient delivery and release of ${ }^{64} \mathrm{Cu}$ into the brain and has potential for PET imaging to study changes in copper ion trafficking associated with $\mathrm{AD}$ and possibly other neurologic disorders. PET imaging with ${ }^{64} \mathrm{Cu}-\mathrm{GTSM}$ showed statistically significant differences in ${ }^{64} \mathrm{Cu}$ global brain uptake and clearance, as well as in brain regional ${ }^{64} \mathrm{Cu}$ concentration and PET image heterogeneity, between TASTPM transgenic mice and age-matched wild-type controls. These results support clinical evaluation of ${ }^{64} \mathrm{Cu}-\mathrm{GTSM}$ PET imaging as a tool to investigate alterations in copper trafficking that might have added value in the diagnosis of $\mathrm{AD}$. 


\section{DISCLOSURE}

The costs of publication of this article were defrayed in part by the payment of page charges. Therefore, and solely to indicate this fact, this article is hereby marked "advertisement" in accordance with 18 USC section 1734. This research was supported by the Alzheimer's Society, Alzheimer's Research U.K., the King's Health Partners Research Challenge Fund, the Whitaker International Program, the Centre of Excellence in Medical Engineering funded by the Wellcome Trust and the EPSRC under grant number WT088641/Z/09/Z, the King's College London and University College London Comprehensive Cancer Imaging Centre funded by CRUK and EPSRC in association with the MRC and DoH (England), and the National Institute for Health Research (NIHR) Biomedical Research Centre based at Guy's and St. Thomas' NHS Foundation Trust and King's College London. PET and SPECT scanning equipment at KCL was funded by an equipment grant from the Wellcome Trust under grant number WT $084052 / Z / 07 / Z$. No other potential conflict of interest relevant to this article was reported.

\section{ACKNOWLEDGMENTS}

We thank GlaxoSmithKline (GSK) for providing the TASTPM mouse model, Dr. Karen Shaw and Dr. Zilin Yu for the production of ${ }^{64} \mathrm{CuCl}_{2}$, Stephen Clark for assistance with in vivo imaging experiments, and Ciara Finucane for advice on the inviCRO brain atlas $\mathrm{NM} / \mathrm{CT}$ module. The views expressed are those of the authors and not necessarily those of the NHS, the NIHR or the Department of Health.

\section{REFERENCES}

1. Rowe CC, Villemagne VL. Brain amyloid imaging. J Nucl Med. 2011;52:1733-1740.

2. Aizenstein HJ, Nebes RD, Saxton JA, et al. Frequent amyloid deposition without significant cognitive impairment among the elderly. Arch Neurol. 2008;65:1509-1517.

3. Josephs KA, Whitwell JL, Ahmed Z, et al. Beta-amyloid burden is not associated with rates of brain atrophy. Ann Neurol. 2008;63:204-212.

4. Hickey JL, Donnelly PS. Diagnostic imaging of Alzheimer's disease with copper and technetium complexes. Coord Chem Rev. 2012;256:2367-2380.

5. Hung YH, Bush AI, Cherny RA. Copper in the brain and Alzheimer's disease. J Biol Inorg Chem. 2010;15:61-76.

6. Kozlowski H, Luczkowski M, Remelli M, Valensin D. Copper, zinc and iron in neurodegenerative diseases (Alzheimer's, Parkinson's and prion diseases). Coord Chem Rev. 2012;256:2129-2141.

7. Eskici G, Axelsen PH. Copper and oxidative stress in the pathogenesis of Alzheimer's disease. Biochemistry. 2012;51:6289-6311.

8. Sayre LM, Perry G, Harris PLR, Liu Y, Schubert KA, Smith MA. In situ oxidative catalysis by neurofibrillary tangles and senile plaques in Alzheimer's disease. J Neurochem. 2000;74:270-279.

9. Smith DP, Smith DG, Curtain CC, et al. Copper-mediated amyloid-beta toxicity is associated with an intermolecular histidine bridge. J Biol Chem. 2006;281: 15145-15154.

10. Angeletti B, Waldron KJ, Freeman KB, et al. BACE1 cytoplasmic domain interacts with the copper chaperone for superoxide dismutase-1 and binds copper. J Biol Chem. 2005;280:17930-17937.

11. Bayer TA, Multhaup G. Involvement of amyloid beta precursor protein (A beta PP) modulated copper homeostasis in Alzheimer's disease. J Alzheimers Dis. 2005;8:201-206.

12. Lovell MA, Robertson JD, Teesdale WJ, Campbell JL, Markesbery WR. Copper, iron and zinc in Alzheimer's disease senile plaques. J Neurol Sci. 1998;158:47-52.

13. Miller Y, Ma BY, Nussinov R. Metal binding sites in amyloid oligomers: complexes and mechanisms. Coord Chem Rev. 2012;256:2245-2252.

14. Faller P, Hureau C. Bioinorganic chemistry of copper and zinc ions coordinated to amyloid-beta peptide. Dalton Trans. 2009;21:1080-1094.

15. Atwood CS, Moir RD, Huang X, et al. Dramatic aggregation of Alzheimer $\alpha \beta$ by $\mathrm{Cu}(\mathrm{II})$ is induced by conditions representing physiological acidosis. J Biol Chem. 1998;273:12817-12826.
16. Cross AJ, Crow TJ, Perry EK, Perry RH, Blessed G, Tomlinson BE. Reduced dopamine-beta-hydroxylase activity in Alzheimer's disease. Br Med J (Clin Res Ed). 1981;282:93-94.

17. Esposito L, Raber J, Kekonius L, et al. Reduction in mitochondrial superoxide dismutase modulates Alzheimer's disease-like pathology and accelerates the onset of behavioral changes in human amyloid precursor protein transgenic mice. J Neurosci. 2006;26:5167-5179.

18. Crouch PJ, Barnham KJ. Therapeutic redistribution of metal ions to treat Alzheimer's disease. Acc Chem Res. 2012;45:1604-1611.

19. Faux NG, Ritchie CW, Gunn A, et al. PBT2 rapidly improves cognition in Alzheimer's disease: additional phase II analyses. J Alzheimers Dis. 2010;20:509-516.

20. Ritchie CW, Bush AI, Mackinnon A, et al. Metal-protein attenuation with iodochlorhydroxyquin (clioquinol) targeting $\alpha \beta$ amyloid deposition and toxicity in Alzheimer's disease: a pilot phase 2 clinical trial. Arch Neurol. 2003;60:1685-1691.

21. White AR, Du T, Laughton KM, et al. Degradation of the Alzheimer's disease amyloid beta-peptide by metal-dependent up-regulation of metalloprotease activity. J Biol Chem. 2006;281:17670-17680.

22. Donnelly PS, Caragounis A, Du T, et al. Selective intracellular release of copper and zinc ions from bis(thiosemicarbazonato) complexes reduces levels of Alzheimer's disease amyloid-beta peptide. J Biol Chem. 2008;283:4568-4577.

23. Crouch PJ, Hung LW, Adlard PA, et al. Increasing Cu bioavailability inhibits Abeta oligomers and tau phosphorylation. Proc Natl Acad Sci USA. 2009;106:381-386.

24. Peng F, Lutsenko S, Sun X, Muzik O. Positron emission tomography of copper metabolism in the Atp7b-/- knock-out mouse model of Wilson's disease. Mol Imaging Biol. 2012;14:70-78.

25. Nomura S, Nozaki S, Hamazaki T, et al. PET imaging analysis with ${ }^{64} \mathrm{Cu}$ in disulfiram treatment for aberrant copper biodistribution in Menkes disease mouse model. J Nucl Med. 2014;55:845-851.

26. Dearling JL, Lewis JS, Mullen GE, Welch MJ, Blower PJ. Copper bis(thiosemicarbazone) complexes as hypoxia imaging agents: structure-activity relationships. J Biol Inorg Chem. 2002;7:249-259.

27. Fodero-Tavoletti MT, Villemagne VL, Paterson BM, et al. Bis(thiosemicarbazonato) $\mathrm{Cu}-64$ complexes for positron emission tomography imaging of Alzheimer's disease. J Alzheimers Dis. 2010;20:49-55.

28. Howlett DR, Richardson JC, Austin A, et al. Cognitive correlates of $\alpha \beta$ deposition in male and female mice bearing amyloid precursor protein and presenilin-1 mutant transgenes. Brain Res. 2004;1017:130-136.

29. Howlett DR, Bowler K, Soden PE, et al. Abeta deposition and related pathology in an APP x PS1 transgenic mouse model of Alzheimer's disease. Histol Histopathol. 2008;23:67-76.

30. Gingras BA, Suprunchuk T, Bayley CH. The preparation of some thiosemicarbazones and their copper complexes: part III. Can J Chem. 1962;40:1053-1059.

31. McCarthy DW, Shefer RE, Klinkowstein RE, et al. Efficient production of high specific activity ${ }^{64} \mathrm{Cu}$ using a biomedical cyclotron. Nucl Med Biol. 1997;24:35-43.

32. Szanda I, Mackewn J, Patay G, et al. National Electrical Manufacturers Association NU-4 performance evaluation of the PET component of the NanoPET/CT preclinical PET/CT scanner. J Nucl Med. 2011;52:1741-1747.

33. Magdics M, Szirmay-Kalos L, Toth B, et al. Performance evaluation of scatter modeling of the GPU-based "Tera-Tomo" 3D PET reconstruction. IEEE Nucl Sci Symp Med Imaging Conf Rec. 2011;4086-4088.

34. Chicklore S, Goh V, Siddique M, Roy A, Marsden PK, Cook GJ. Quantifying tumour heterogeneity in ${ }^{18} \mathrm{~F}$-FDG PET/CT imaging by texture analysis. Eur J Nucl Med Mol Imaging. 2013;40:133-140.

35. Cook GJ, Yip C, Siddique M, et al. Are pretreatment ${ }^{18}$ F-FDG PET tumor textural features in non-small cell lung cancer associated with response and survival after chemoradiotherapy? J Nucl Med. 2013;54:19-26.

36. Mathias CJ, Bergmann SR, Green MA. Development and validation of a solvent extraction technique for determination of Cu-PTSM in blood. Nucl Med Biol. 1993;20:343-349.

37. Xiao Z, Donnelly PS, Zimmermann M, Wedd AG. Transfer of copper between bis(thiosemicarbazone) ligands and intracellular copper-binding proteins: insights into mechanisms of copper uptake and hypoxia selectivity. Inorg Chem. 2008;47:4338-4347.

38. Price KA, Crouch PJ, Volitakis I, et al. Mechanisms controlling the cellular accumulation of copper bis(thiosemicarbazonato) complexes. Inorg Chem. 2011;50: 9594-9605.

39. Syme CD, Nadal RC, Rigby SE, Viles JH. Copper binding to the amyloid-beta $(\alpha \beta)$ peptide associated with Alzheimer's disease: folding, coordination geometry, $\mathrm{pH}$ dependence, stoichiometry, and affinity of $\alpha \beta-(1-28)$ : insights from a range of complementary spectroscopic techniques. J Biol Chem. 2004;279:18169-18177.

40. Jiang D, Zhang L, Grant GP, et al. The elevated copper binding strength of amyloid-beta aggregates allows the sequestration of copper from albumin: a pathway to accumulation of copper in senile plaques. Biochemistry. 2013;52: $547-556$. 